\title{
Recruiting, Retaining, and Graduating African American's from a PGA Golf Management Program
}

\author{
Billy Dillon \\ Associate Professor \& Director \\ PGA Golf Management Program \\ University of Maryland Eastern Shore \\ Kiah Hall, 2100 \\ Princess Anne, MD 21813
}

\section{Primary Review}

As the golf industry exploded in the late 1990's, the PGA of America (PGA) saw the need to keep up with the demand and became proactive in creating qualified individuals to work within the industry by expanding the number of accredited PGA Golf Management Programs at selected universities across the country. From 1975 to 1998 only four universities held PGA of America accreditation. From 1999 to 2008, the PGA of America added 16 universities to the fold. (Table 1)

\begin{tabular}{|l|l|}
\hline $\begin{array}{l}\text { PGA Golf Management } \\
\text { University }\end{array}$ & $\begin{array}{l}\text { Initial Accreditation } \\
\text { Year }\end{array}$ \\
\hline Arizona State University & $\mathbf{1 9 9 9}$ \\
\hline Campbell University & $\mathbf{1 9 9 9}$ \\
\hline Clemson University & $\mathbf{2 0 0 1}$ \\
\hline Coastal Carolina University & $\mathbf{1 9 9 9}$ \\
\hline Eastern Kentucky University & $\mathbf{2 0 0 6}$ \\
\hline Ferris State University & 1975 \\
\hline Florida Gulf Coast University & $\mathbf{2 0 0 5}$ \\
\hline Florida State University & $\mathbf{1 9 9 9}$ \\
\hline Methodist University & $\mathbf{1 9 9 9}$ \\
\hline Mississippi State University & 1985 \\
\hline New Mexico State University & 1987 \\
\hline North Carolina State University & $\mathbf{2 0 0 2}$ \\
\hline Pennsylvania State University & 1990 \\
\hline Sam Houston State University & $\mathbf{2 0 0 5}$ \\
\hline University of Central Oklahoma & $\mathbf{2 0 0 8}$ \\
\hline $\begin{array}{l}\text { University of Colorado: } \\
\text { Colorado Springs }\end{array}$ & $\mathbf{2 0 0 3}$ \\
\hline University of Idaho & $\mathbf{2 0 0 2}$ \\
\hline $\begin{array}{l}\text { University of Maryland Eastern } \\
\text { Shore }\end{array}$ & $\mathbf{2 0 0 8}$ \\
\hline University of Nebraska & $\mathbf{2 0 0 4}$ \\
\hline University of Nevada Las Vegas & $\mathbf{2 0 0 2}$ \\
\hline
\end{tabular}

(Table 1)

With this unprecedented growth, the PGA of America began the process of an honest and deliberate evaluation of diversity and inclusion issues within the industry. This evaluation led the PGA of America to the conclusion that if the game was going to continue to grow then there needs to be greater representation of people of color within the game and industry. In 2008, the PGA took a bold step and added the PGA Golf Management Program at the University of Maryland Eastern Shore (UMES), a Historically Black College or University (HBCU). This strategic move showed the world that the PGA was taking an aggressive approach in improving the number of African American members in the association. The underlying mission of the PGA Golf Management Program at UMES is to assist the PGA in raising the overall membership numbers of African Americans within the association. 
This mission was fully embraced by UMES, however, is has come with some unforeseen challenges that the other 17 PGA Golf Management Programs do not deal with on a day to day basis. These challenges include the recruiting, retention, and graduation processes of African Americans within the program. Many of the PGA Golf Management programs attempt to recruit minorities into their programs. However, due to the vision of the UMES PGA Golf Management program, there is an expectation to enroll a high number of African Americans into the program.

\section{UMES PGA Golf Management Vision Statement}

We aspire to be a premiere golf management program that upholds the traditions and highest standards of the PGA of America, while being at the forefront in producing diverse leaders in the golf profession and industry.

\section{Recruiting}

Michael Lomax (2000), Assistant Professor in Sports Management at the University of Georgia, argues that there is a need for African Americans to pursue careers in sport management, marketing, or promotion. He states that Africa American students are mostly unaware that such degree programs in colleges and universities exist and that sport management faculty makes little or no effort to recruit minorities for their programs. Lomax (2000) documented the appearance of a lack of interest in minority recruitment and retention within sport management programs across the United States.

UMES remains the only HBCU in the world that offers PGA Golf Management as a degree program. Recruiting students into the UMES PGA Golf Management Program has proved challenging for administration. First, it is difficult to enroll white students because they typically do not want to attend a majority black university. Second, it is challenging to find African American students that have the qualifications to be accepted into a PGA Golf Management Program, including the 12 handicap maximum requirement stipulated by the PGA Standards for the Accreditation of PGA Golf Management University Programs. This requirement has been put in place to ensure student success in passing the PGA of America's Playing Ability Test (PAT). Many in the industry question why with the emergence and popularity of Tiger Woods, this has not produced more African American golfers into the games highest levels. The variables for the lack of exceptional African American golfers are numerous. These same variables affect the recruiting efforts of the PGA Golf Management Program, which in turn slows the growth in the number of African American's that become PGA of America members.

This literature review will focus on the variables that have an effect on the number of African Americans entering the game of golf and seeing the golf industry as a viable career option. These variables include career expectations, how they view themselves in society, parental/guardian support for golf, cultural preferences, and spatial accessibility.

\section{Career Expectations}

One of the most formidable questions one receives during childhood is, what do you want to be when you grow up? The answer to this question changes many times as one grows and enters the teenage years. The socialization process we go through helps us answer this question. Socialization agents include family, role models, neighborhood, media, gender roles, and community in general. The socialization process of African American males has been geared toward athletics and other forms of entertainment (Winbush, 1987). African American males are socialized by family and the larger community into sports deliberately and intensively by limiting exposure to other hobbies and role models and pushing sports as a possible career path early in life (Edwards, 1983). The sport's most often prioritized in the African American community are football and basketball. Edwards (1983) argues that sports participation is overemphasized among African American boys and men and diverts attention and efforts away from academic engagement. The consequences of overemphasizing athletic participation are lower levels of academic achievement, higher expectations for professional sports careers as a means toward mobility and economic viability, highly salient athletic identities, and lower levels of career maturity (Lomax, 2000). Sports can impede success in the classroom and also enhance success in the classroom. A driving force in the expectations for African American males to become professional athletes is the promise of athletic college scholarships, lucrative professional careers, and fame. However, involvement in athletics can decrease interest in academic engagement and reduces aspirations for pursuing success through educational attainment. For many African American youth, education matters only to the extent that maintaining eligibility to participate in sports in elementary and secondary schools through college is necessary in order to fulfill externally imposed requirements. Devoting efforts and energies to be fully engaged in the learning process is secondary to development as an athlete (Dawkins, 2009). On the other hand, Rasmussen (2000) states that participation in sports can increase academic engagement and success by enhancing mobility indirectly by operating as a protective factor against deviant behaviors and promoting such valued assets as maintaining exercise and fitness, and developing the ability to handle adversity and contribution to teamwork and sportsmanship. 
If there is such a high priority placed on African American males to participate in sports to earn college scholarships and move onto the professional ranks, then why don't more African American youth choose golf?

The issue of racial minority underrepresentation in golf is a complex, multifaceted phenomenon that requires a more comprehensive analysis into a myriad of factors that contribute to our understanding of this problem (Rosselli \&Singer, 2015). Potential explanations for this underrepresentation of minorities in golf are racial minorities' cultural preferences for certain leisure activities and sports (Harrison, Lee, \& Belcher, 1999), and communities from which racial minorities come from do not place a high value on the game of golf. Since 2010, UMES PGA Golf Management students have introduced the game of golf to numerous elementary and middle school aged children from Princess Anne, Maryland only to be told later that the parents/guardians have discouraged these children from playing golf. Other explanations for underrepresentation of minorities in golf are the relatively high cost of participation in golf is a major factor for African Americans and Hispanics, who earn less income when compared to their White and Asian counterparts (Cunningham, 2011) and access discrimination including Whites-only membership policies at some golf courses and country clubs in the years after legal segregation. Although these policies are not commonplace today, the attitudes and cultures of these facilities resonates as unwelcoming.

Although sports participation is highly emphasized in the African American community, golf is not considered as a viable alternative to traditional activities (i.e. football and basketball) due to cultural preferences, lack of value placed on golf, relatively high costs associated with the game, and access discrimination. These variables, when added together, give clarity to the lack of minority participation in the game of golf which leads to a low number of minorities entering the golf industry workforce. This lack of representation sends a message to young black athletes that career aspirations within the golf industry are not an option for them (Lomax, 2000).

\section{How they view themselves in society}

It is difficult for young African Americans to find where they fit within the golf industry. As the UMES PGA Golf Management Program staff meets with potential students and their parents, a typical question from the parents is "Will my child be taken seriously when looking for employment in the golf industry?" UMES has been graduating students from the program since December 2012. The first African American didn't graduate until December 2013. Since that time that Alumnus has been employed at The Suburban Club in Pikesville, MD, just north-west of downtown Baltimore. Currently, UMES has graduated eleven people of color and all have gone on to become PGA members and are employed at mostly private clubs across the country, from Maryland to California. We do have a positive answer for parents that ask the aforementioned question, upon graduation your child will be taken seriously and will find fulfilling employment in the golf industry. That is great news as we go through the student recruiting process and the PGA of America pushes growth of the game initiatives. The theory is that in order for the industry to attract new people to the game, it will be helpful if the people that work in the pro-shops look like the people that are being targeted for participation. However, one has to wonder why that question needs to asked by parents in the first place. We have never had a Caucasian family ask that question.

To understand why students and parents of African American students ask this particular question stems from the history of the game towards minorities and how minorities view themselves in today's society. Explicit forms of prejudice against racial minorities might not be as prevalent in the golf industry today as it has in past decades, however, the presence of implicit forms of prejudice could still lead to access and treatment discrimination against racial minorities who might be seeking membership or inclusion in clubs or organizations (Rosselli \& Singer, 2015). African Americans that do play golf are keenly aware that historically, many golf courses, particularly private golf and country clubs, have embraced cultures of similarity where the focus has been on the recruitment and selection of members into these organizations who are from White, affluent families, not racial minority communities. If leaders in the golf industry organizations embrace a culture of diversity as opposed to a culture of similarity, there is a greater likelihood that there might be an increase in racial minority representation among golf participants (Doherty \& Chelladurai, 1999). In addition, these same golf industry leaders from governing bodies, media, sporting goods stores, nonprofit organizations, high school and college golf programs, and especially golf clubs, courses, a resorts are in a position to significantly and meaningfully impact the representation of racial minority golf participants (Schein, 1985). There is a need to start a marketing campaign to demonstrate to the underrepresented groups in golf that industry organizations desire to include and value them as golf participants, media personalities, fans, and other important stakeholders of the game. This might allow organizations in the golf community to meaningfully address prejudice and discrimination and move away from cultures of similarity to cultures of diversity (Evans, 2013). Racial minorities typically come from homes and communities that have an affinity toward certain sports (i.e. football and basketball). 
This type of influence could certainly have a strong impact on these individuals self-concept or how they see themselves in society, and, consequently, whether or not they become in-group or out-group members within the golf industry (Rosselli \& Singer, 2015). Young black men from disadvantaged neighborhoods often find it difficult to escape. They have fewer opportunities for role models, and they are more deeply embedded in and dependent upon delinquent peer groups and the illicit economy that flourishes in their neighborhoods, which typically does not include the game of golf (Elliott, 1994). African American children see very few lawyers, doctors, teachers, or scientists of their own race in the media or in life (Edwards, 1983).

In a 2015 study by Conchas, Lin, Oseguera, and Drake, the researchers documented that African American youth do not see academic possibilities as being limitless to them. This affects how they see themselves in society. Students in the research sample reported an awareness of the negative views of African Americans held by those outside of the African American community. The students reported feeling a strong effect from racial stereotypes on their career aspirations and expectations. They stated that the stereotypes placed upon them by society for being African American are that they are loud, violent, gang-bangers, shoot people, get sent to jail, use drugs, and that they were viewed as possessing undesirable characteristics that clash with social norms. Seeing themselves in this light is detrimental to academics. From the moment they step on campus they typically feel inferior because they are African American and with having to deal with the stereotypes, they tend to steer away from academic programs in which they feel they do not belong. In short, it is nearly impossible to view African American students on campus without the stereotypes of Black people in America (Harrison, 2008). These stereotypes forces African Americans to believe that it is hard to get a fair shake in the job market, especially in fields that they do not typically work, like the golf industry.

\section{Parental/Guardian Support for Golf}

The UMES PGA Golf Management Program students must complete at least one community service project every semester as a PGA Golf Management Student Association (PGMSA) requirement. In the 17 semesters of the programs existence, the PGMSA has completed this requirement by twice hosting junior golf clinics at the Garland Hayward Center in Princess Anne, Maryland. The UMES students use the Starting New at Golf (SNAG) golf system to introduce the game to the youth at the Garland Hayward Center. The juniors have seemed to be engaged with the clinics as most of them have never been introduced to the game of golf in the past. They know who Tiger Woods is, but that is the extent of their golf knowledge. The clinics run until 5:30 pm when the juniors are being picked up for the day. As the juniors were being picked up, the UMES students witnessed some juniors talking to their parent/guardian about playing golf that day. The parent/guardian then tells the junior that golf is nice but it is not something that they should want to do, they need to play football or basketball. This is a sad reality of what happens when junior minorities are introduced to the game. Introducing the game is the easy part, retaining them in the game is the hard part. We have found that even if the junior shows an interest in the game of golf during the clinic, the chances of the parent/guardian taking the next step by allowing the junior to continue playing are non-existent. The main reason for this parental/guardian reaction is that they themselves do not know much about the game of golf, or who to turn to for building relationships and helping in mentoring process of the student.

Understanding the relationship between coaches and African American male youth is important for several reasons. In most urban communities, youth sports are often the only organized activity for young African American males. Data indicates that single parents account for $67 \%$ of all households in the African American community, leaving the burden of many single mothers to raise African American boys alone. As a result, single mothers may seek out youth organizations to expose their adolescent sons to conventional adult male role models (Richardson, 2012). With this being the case, why would the mother of a African American youth seek out a PGA Professional to give lessons to and mentor their son in a game that they do not understand? Richardson (2012) suggests that social distrust among adults affects the ability of parents to develop relationships with other conventional adult role models who may assist in childrearing. It would be difficult to for a single African American mother to turn her young son over to someone that looks nothing like her or shares the same social status and trust that person to have her child's best interests at heart. Parents invest interpersonal trust in other adults both within and outside of the family. Within social networks of lowincome parents, particularly single mothers, trust, support, and reciprocity are important forms of social control which are critical to the survival of families and children in high-risk neighborhoods (Richardson, 2012).

The basic reasons that the parents/guardians of black youth do not support participation in the game of golf are the game is not embedded in the black culture and that it is difficult for parents/guardians to find someone that they wholeheartedly trust with the mentoring process of their youth. If the parents/guardians do allow the junior to pursue the game of golf it is usually a situation where someone in the family plays the game, has an understanding of the game, and knows the characteristics of a particular coach that can foster interpersonal trust between the parents/guardians, the junior golfer, and themselves. 


\section{Cultural Preferences}

The game of golf simply is not embedded in African American culture. Despite representing 13\% of the U.S. population, blacks make up only 4\% of the U.S. golf population (National Golf Foundation, 2001).

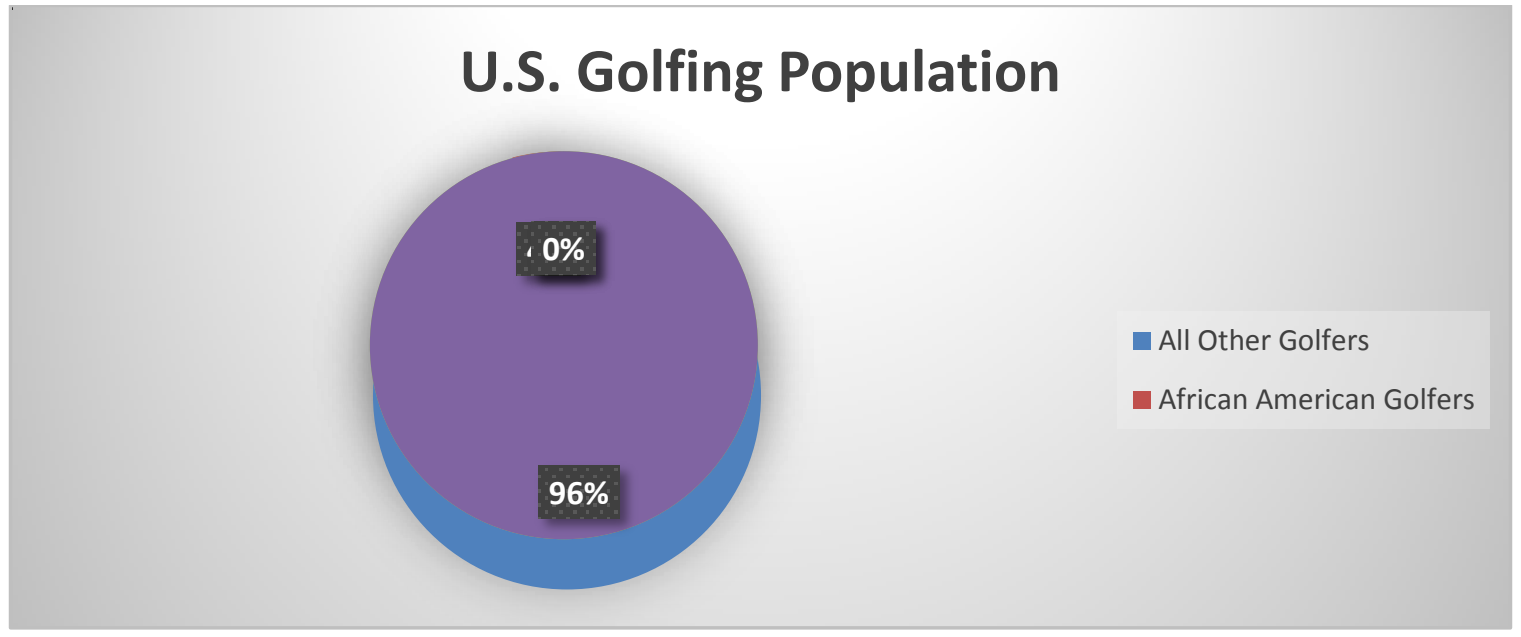

(Table 2)

Even with the low percentage of African American golfers, UMES has enrolled 59 African American students since its inception in 2008. Each of these students were introduced to the game by either parents, grandparents, or took an interest in the game due to the success of Tiger Woods. It has been stated numerous times over the years by a handful of my African American students that "If it were not for Tiger, I wouldn't be playing golf right now".

Growing the game of golf in a culture that historically doesn't accept the game is very challenging. The golf industry wants to put the past behind and just look forward, however, it is difficult for the African American community to look at golf without skepticism. After all, it was the golf industry itself that kept people of color from participating in the game through the "Caucasian Only" clause and the exclusivity of golf and country clubs all over the nation. Cost, time, and perceived discrimination were consistent factors in determining the minority under-representation in golf (Mitchelson \& Lazaro, 2004).

Mitchelson and Lazaro (2004) argue that the major entities of the golf industry (PGA, USGA, and others) are concerned about the lack of African American professional golfers and the small number of African Americans working in the industry because a vast sum of money is at stake. The fact that much of golf's revenue growth is associated with television coverage also pressures the industry to diversify, due to sponsor and advertiser expectations (Sterba, 2000). Approximately $25 \%$ of PGA sponsors' gross revenues come from African American patrons. There is also the feeling amongst some that if golf can be exported to the inner city, then African American kids can be raised in a socially appropriate way, thus, golf can be seen to represent a kind of cultural imperialism (Stossel 1998).

For the game to grow in the African American community there must be role models either playing golf professionally or working in the industry. It is important for those interested in picking up the game to see people that look like them playing and working to gain a comfort level of belonging. Dawkins (2003) states that Tiger Woods' recognition of pioneering black golfers on the occasion of winning golf's most coveted award clearly identified him as part of the continuing legacy of African American golfers. It has also stimulated interest in promoting more African American inclusion in the sport. By linking his accomplishments to African American "historical role models" and the continuation of the Black golf legacy, current programmatic efforts to introduce and stimulate interest in golf as a career pursuit among African American youth can clearly benefit (Dawkins, 2003). I argue that golf in 2018 is as inclusionary as it can be, it can't get any more inclusionary. The industry would grow with more diversity but the industry no longer holds people back from enjoying the benefits of the game. Excluding some private clubs, anyone that wants to play can play.

While the PGA has been sometimes stigmatized as the last professional organization in sports to remove the formal barrier of racism, ironically, golf has mounted a more aggressive effort than other professional sports to increase participation of Black youth by supporting The First Tee Programs (Dawkins, 2003). As other programs are introduced and UMES sends more African American's into the industry as PGA Professionals, hopefully, one day there will be a shift in the African American culture and Black youth will see golf as a viable career option. 


\section{Spatial Accessibility}

The golf industry claims that it wants more diversity and inclusion in the game, that people of color and other minorities will feel more comfortable visiting golf facilities as patrons if they see someone that looks like them working in the pro-shop. This is difficult to achieve as most golf facilities are not constructed near African American communities. Throughout the PGA Golf Management educational curriculum one will find that managers are taught that understanding their market is crucial to success. Therefore, one assumption that can be made is that golf course owners, if they understand their market, will most likely construct their facility in an area that will help them maximize revenue and profits. These golf courses will not be found in African American populated areas leaving a lack of special accessibility to one of the very demographic groups that the golf industry claims they want to see grow.

Even with the possible relaxation of social and economic constraints, like discrimination and income inequalities, the comparative special configuration of the landscapes of production and consumption could inhibit African American participation in golf (Mitchelson \& Lazaro, 2004). One can argue that African American communities are more concentrated than the white population leaving a shortage of inner city courses. Inner-city courses are limited due to land availability and the cost of the property itself. Today, according to JJ Keegan, Golf Convergence, $20 \%$ of the country is underserved in golf and $80 \%$ of the country is overserved in golf. The $20 \%$ underserved will be found mostly near large metropolitan areas like New York City, Washington, and Chicago. Some private clubs in these areas currently have waiting list for membership. It is ironic that the areas of the country that are underserved and don't necessarily need to grow also happen to be near African American communities. In the simplest terms, gross accessibility to golf consistently decreases as the percent of African Americans increase.

One of the few notable projects that targets inner-city youth into the game of golf is The First Tee. The First Tee, started as a way to bring an affordable junior golf program to communities that did not have them, especially in economically disadvantaged areas. One of the misconceptions of The First Tee is that they originated to grow the game of golf in underserved areas. In reality, The First Tee teaches life skills to youth through the game of golf.

First Tee Mission Statement: Our mission is to impact the lives of young people by providing educational programs that build character, instill life-enhancing values and promote healthy choices through the game of golf.The First Tee has been inexistence for 20 years and has been successful in fulfilling their mission. The First Tee Programs reach youth, teach them life skills, and a little about the game of golf. Questions have been raised as to whether The First Tee participants continue to play the game of golf once they leave the program and enter the workforce, military, or college. Finding the answer to this question would be an interesting research project. The bottom line is that until the game of golf becomes embedded in African American culture, and The First Tee alumni could help make this a possibility, it will always be a struggle to grow golf in the black community.

\section{Retaining:}

The UMES PGA Golf Management Program has battled through the barriers that keep African Americans from the game of golf and have enrolled a number of black students over the last ten academic years. Now that we have them, how do we ensure that we retain them? It has been our experience that a number of African American students that have enrolled in the UMES PGA Golf Management Program arrive with questions of how they will be treated within the program. Mostly the male students come in with trust issues. It took me a long time to understand that these students come to UMES and are not sure of what to expect out of us as their teachers, advisors, and coaches. The faculty and staff within the PGA Golf Management Program is all white, including two white, male PGA Professionals and one white, female Administrative Assistant. It took about five years for me to realize that we (faculty/staff) represent everything that these young students have been told is against them their entire lives. We represent, white, middle class, conservatives. There is no reason for these students to come to UMES at 18 years of age, with their backgrounds, and trust that we have their best interests at heart. I always assumed that the students coming in would know that because they chose UMES that they would trust us from the beginning. There is a definite difference in the reaction we get from African American females compared to males. Females enter the program open minded, wanting to learn as much as they can and get involved as much as possible. The males tend to come in a little more cautious and they feel their way through the first year. While males entering the program in a cautious manner and females begin open minded, it is easy to see why retention needs to be handled in a consistent manner. We never want to lose a student for any reason, but the reality is, all programs lose students along the way. However, if you can get the student through the Qualifying Level and Level 1, you have a much better chance of retaining that student. If you are going to lose a student, the majority of the time it will be in the Level 1 stage of the education process.

Trust plays a huge role in the retention of African American students. As stated, it is easier to retain African American females than males. Males come in questioning our motives and ask themselves, does the staff here truly want to help me graduate, enter the industry, and become productive members of the PGA of America? 
Of course the answer is yes, but how do I as the leader of the program make them understand that no matter what happens, I want to see them attain their goals.

The first step is to identify the students level of cautiousness as they enter the program. Some students come in without any worries and some are on the opposite side of the spectrum where we have to prove to them that we want to help them attain their personal goals, and earn their trust. In some case's I relate it to being a Sargent in the Army, where I have to break down the student and rebuild them with the trust being a main variable. A characteristic feature of mentoring relationships is that they involve mutual trust (Larson, 2006). Most of these case's deal with the African American males from the inner cities (Baltimore, Washington DC, Detroit, New Orleans, and San Diego) that have enrolled in the program. Initially we (i.e. faculty/staff) must reach a comfort level with the parents before the parents agree to send their child to UMES.

Richardson (2012) argues that parents invest interpersonal trust in other adults both within and outside of the family. Within social networks of low-income parents, particularly single mothers, trust, support, and reciprocity are important forms of social control which are critical to the survival of families and children from high-risk areas. When individuals interact regularly and trust one another, social relationships are more productive. Interpersonal trust is critical in facilitating action and cooperation for the mutual benefit of individuals within a social network. Individuals with active and trusting connections to other community members develop positive character traits. Moreover, individuals in relationships with high levels of social trust can get things done more easily and efficiently, including things that are of personal benefits (Jarrett et al., 2005).

The second step is to figure out each individual students needs and concerns, usually based on culture. Once these needs and concerns are filtered, we can then create more culturally sensitive instruction. For example, when teaching golf operations, the students will grasp a better understanding of the material if I relate it to a municipal or daily fee golf course as opposed to a high end private club. Teachers can be significant in their delivery of information to students if they use the cultural background of the student (Roberson, 2003).

Third, and possibly the most important, is understanding the African American culture in America. Although, I will never state that I understand what these students go through being African American in this country. However, based on conversations and building trust with the students, I can empathize. Over the past 20 years, all of golf including the PGA of America, the Club Managers Association America, the World Golf Foundation, the United States Golf Association, and the Golf Course Superintendents Association of America have been calling for more diversity in the game. It is great to have African American youth enroll in any of the PGA Golf Management Programs. What must be understood is that golf is not as socially acceptable in their culture as it is in white America. It is no wonder why these young men enter these programs so confused. First, they don't trust us (faculty/staff) as mentors and they may be being looked down upon in their own culture for entering a white man's world. Harrison, Martin, and Fuller (2015) completed a study on self-determination theory that examined the influence of peers on academic experiences. Including peer groups into an examination of African American academic experiences is critical as researchers have argued that African Americans, particularly African American males, devalue academic achievement owing, in part, to a fear of being socially ostracized and ridiculed by their peer group (Fordham \& Ogbu, 1986). In contrast, Harper (2006) argues that peer support is vital to the academic success of high-achievers. Therefore, it is plausible to expect academically driven African American students to be motivated and supported by peers with like-minded values, goals,and academic interest (Austin, 1993). The self-determination theory study participants knew their life aspirations and understood it was vital to choose majors that supported their ambitions. They knew what it meant to take control of their college experience and internalized that meaning with their aspirations. As a result, they experienced autonomy and enhanced intrinsic motivation (Harrison, Martin, and Fuller, 2015). This is why it is important for us to create a family atmosphere within the PGA Golf Management Program. It is imperative that all students support each other while respecting their individual backgrounds and cultures in order to cultivate success for all students. 
The UMES PGA Golf Management Program employs the following retention activities:

\begin{tabular}{ll|}
\hline 1) & Timely student advising utilizing student's electronic audit to guide the process. \\
\hline 2) & $\begin{array}{l}\text { Utilization of the PGA Knowledge Center to track student progress through the PGA Golf } \\
\text { Management Program requirements to assess student success in the same manner as } \\
\text { academic advising. }\end{array}$ \\
\hline 3) & $\begin{array}{l}\text { Create strong peer support groups that help students academically, personally, and } \\
\text { emotionally. }\end{array}$ \\
\hline 4$)$ & $\begin{array}{l}\text { As a unit, the faculty and staff work to provide students a first line of defense support center } \\
\text { and family oriented atmosphere in which they can feel comfortable and thrive. This entails } \\
\text { open door polices, addressing concerns in a timely manner, encouraging students to visit the } \\
\text { office, and providing space where they can study and relax. }\end{array}$ \\
\hline 5) & Encourage of study groups whereby faculty is available to assist. \\
\hline 6$)$ & $\begin{array}{l}\text { Player Development Program whereby students work directly with faculty one-on-one at } \\
\text { most three-to-one. }\end{array}$ \\
\hline 7) & $\begin{array}{l}\text { Encouragement to utilize UMES Academic Support Centers to include the Writing Center } \\
\text { and Tutoring. }\end{array}$ \\
\hline 8) & $\begin{array}{l}\text { Speaker Series Program whereby speakers in the golf industry speak to students about the } \\
\text { importance of core value in life as well as on the golf course. }\end{array}$ \\
\hline 9) & $\begin{array}{l}\text { Golf related activities for students that offer networking and relationship building, cultivating } \\
\text { one's own talent within the context of team play, school pride, and sportsmanship. }\end{array}$ \\
&
\end{tabular}

(Table 3)

\section{Graduating:}

Between December 2012 and May 2019, the PGA Golf Management Program at UMES has graduated 53 total students, 20 of which are minority (19 African Americans and 1 Korean), three of the 20 are female; 16 are currently working in the golf industry.

UMES PGA Golf Management Minority Graduates (2012-2019)

\begin{tabular}{|l|l|l|l|l|}
\hline Graduate \# & Year & Race & Gender & Employment Facility Type \\
\hline 1 & Fall 2013 & Asian & M & Public (Korea) \\
\hline 2 & Spring 2014 & AA & M & Public \\
\hline 3 & Spring 2014 & AA & M & Private \\
\hline 4 & Spring 2015 & AA & M & Private \\
\hline 5 & Fall 2015 & AA & M & Private \\
\hline 6 & Spring 2016 & AA & F & Not in Industry \\
\hline 7 & Spring 2016 & AA & M & Private \\
\hline 8 & Spring 2016 & AA & M & Private \\
\hline 9 & Fall 2016 & AA & M & Public \\
\hline 10 & Fall 2016 & AA & M & Resort \\
\hline 11 & Fall2016 & AA & M & Public \\
\hline 12 & Fall 2017 & AA & F & Public \\
\hline 13 & Spring 2018 & AA & M & Public \\
\hline 14 & Spring 2018 & AA & M & Not in Industry \\
\hline 15 & Fall 2018 & AA & M & Off Course \\
\hline 16 & Fall 2018 & AA & F & Off Course \\
\hline 17 & Fall 2018 & AA & M & Not in Industry \\
\hline 18 & Fall 2018 & AA & M & Off Course \\
\hline 19 & Fall 2018 & AA & M & Not in Industry \\
\hline 20 & Spring 2019 & AA & M & Private \\
\hline
\end{tabular}

(Table 4)

African American male college students are considered one of the most at risk students on campus, having the lowest graduation rates of any other demographic group (The Journal of Blacks in Higher Education, 2012). With very few African American PGA of America members, these students are restricted in finding role models to help get them to graduation. 
Other barriers to graduation for African American students in the PGA Golf Management Program at UMES include racial isolation within the program, racism, and stereotyping. All of these factors affect the psyche of how one sees themselves and the success that they can gain after graduation. According to Beamon (2012), race seems to effect athletic identity foreclosure among athletes similar to the manner in which it has been found to play a role in other areas such as career maturity, sports socialization, sports career aspirations, and student-athletic academic success, with African Americans having a more difficulty experience than Whites in all of the above mentioned areas.

The question remains, once these students graduate, will they be taken seriously within the golf industry? As six of our graduates are currently working at private facilities, I believe that as assistant professionals in entry level positions, they will get serious consideration for employment. Above that, it remains to be seen. Currently, there is no African American PGA Member serving as the Head Golf Professionals at a private facility in the United States.

However, as the applicant pool is extremely limited, we can't expect there to be many African American Head Professionals at private or public courses. I believe that as long as we keep recruiting, retaining, and graduating African Americans from the PGA Golf Management Program at UMES, opportunities will be available to those that go on to become positive, productive members of the association and change will happen. As long as young African Americans can see that people that look like them have successful careers in the golf industry, change will happen.Just as the PGA of America and the entities of golf have supported female participation in the game, they must keep being vigilant is an effort to increase African American participation. In November 2018, the first female President of the PGA of America was elected. If the efforts are kept up hopefully one day, a UMES African American PGA Golf Management graduate will be elected to national office.

\section{References}

Astin, A.W. (1993). What matters in college? Four critical years revisited. San Francisco,CA. Jossey-Bass.

Beamon, K. (2012). "I'm a Baller": Athletic Identity Foreclosure among African 208

Conchas, G., Lin, A., Oseguera, L., and Drake, S. (2015). Superstar or Scholar? African

American Male Youths' Perceptions of Opportunity in a Time of Change. UrbanStudies, 50(6), 660-688.

Cunningham, G.B. (2011). Diversity in sport organizations. ( ${ }^{\text {nd }}$ ed.). Scottsdale, AZ: Holcomb-Hathaway.

Dawkins, M.P., Braddock, J.H., Celaya, A. (2009). Academic Engagement among African American Males Who Hold Aspirations for Athletic Careers in Professional Sports.Journal of Negro Education, 93: 51-65.

Dawkins, M.P. (2003). Race Relations and the Sport of Golf: The African American Golf Legacy. The Western Journal of Black Studies. 27(4), 231-235.

Doherty, A.J., and Chelladurai, P. (1999). Managing cultural diversity in sport organizations: A theoretical perspective. Journal of Sports Management. 13, 280-297.

Edwards, H. (1983). The exploitation of Black athletes. AGB Reports. 28, 37-48.

Elliott, D.S. (1994). Serious violent offenders: Onset, developmental course, and termination-The American Society of Criminology 1993 presidential address.Criminology. 32, 1-21.

Evans, F. (2013). Sheila Johnson poised for key role. Retrieved from http://espn.go.com/espn.

Fordham, S. and Ogbu, J.U. (1986). Black students' success: Coping with the burden of "acting White". Urban Review, 18, 176-207.

Harrison, C.K. (2008). "Athleticated” Verses Educated: A Qualitative Investigation of Campus Perceptions, Recruiting and African American Male Student-Athletes.Challenge. 39-60.

Harrison, C.K., Martin, B.E., Fuller, R. (2015). "Eagles Don't Fly with Sparrows": Self-

Determination Theory, African American Male Scholar-Athletes and Peer Group Influences on Motivation. The Journal of Negro Education. 84(1). 80-93.

Harrison, L., Lee, A., and Belcher, D. (1999). Self-schemata for specific sports and Physical activity: The influence of race and gender. Journal of Sport \& Social Issues. 23, 287-307.

Harper, S.R. (2006). Peer support for African American male college achievement: Beyond internalized racism and the burden of “acting White”. Journal of Men'sStudies. 14, 337-358.

Jarrett, R.L., Sullivan, P.J., and Watkins, N.D. (2005). Developing social capital through Participation in organized youth programs: Qualitative insights from three programs. Journal of Community Psychology. 33(1), 41-55.

Larson, R. (2006). Positive youth development, willful adolescents, and mentoring. Journal of Community Psychology. 34(6), 677-689.

Lomax, M.E. (2000). Athletics vs. Education: Dilemmas of Black Youth. Society .March/April, 21-23.

Mitchelson, R. L., and Lazaro, M.T. (2004). The Face of the Game: African Americans' Spatial Accessibility to Golf. Southeastern Geographer. 44(1), 48-73.

Rasmussen, K. (2000). The Changing Sports Scene. Educational Leadership. 57, $26-29$.

82 
Richardson, J.B. (2012). Beyond the Playing Field: Coaches as Social Capital for Inner City Adolescent African American Males. Journal of African American Studies.16, 171-194.

Roberson, V. (2003). African American Culture and Physical Skill Development Programs: The Effect on Golf After Tiger Woods. Journal of Black Studies.33(6), 801-816.

Rosselli, A. and Singer, J.N. (2015). Toward a Multilevel Framework to Examine the Underrepresentation of Racial Minorities in Golf within the United States. Quest.67, 44-55.

Schein, E. (1985).Organizational culture and leadership. San Francisco, CA. Jossey-Bass.

Sterba, J.P. (2000). Golf is booming-Except that it isn't unless you count TV. Wall Street Journal. 235(74), A1.

Stossel, S. (1998). The golfing of America. New Republic. 219(5), 18-21.

The Journal of Blacks in Higher Education. (2012). Black student graduation rates remain low, but modest progress begins to show. Retrieved from hppt://www.jbhe.com/features/50_blackstudents_graduate.html.

Winbush, R.A. (1987). The furious passage of the African American intercollegiate athlete.Journal of Sport and Social Issues. 11, 97-103. 